\title{
Effects of microcurrents and physical exercise on the abdominal fat in patients with coronary artery disease
}

Andreia Noites; Joana Pinto; Carla Patrícia Freitas; Cristina Melo; Aníbal Albuquerque; Madalena Teixeira; Fernando Ribeiro; José Mesquita Bastos

\begin{abstract}
Introduction

Coronary artery disease is associated with decreased levels of physical activity, contributing to increases in abdominal fat and consequently increasing metabolic risk. The innovative use of microcurrents may be an effective method to increase the lipolytic rate of abdominal adipocytes. This study aimed to investigate the effects of utilizing microcurrents in a home-based exercise program in subjects with coronary artery disease to assess changes in total, subcutaneous and visceral abdominal adipose tissue.
\end{abstract}

\section{Methods}

This controlled trial included 44 subjects with myocardial infarction, randomly divided into Intervention Group 1 (IG1; $n=16)$, Intervention Group 2 (IG2; $n=12$ ) and Control Group (CG; $n=16)$. IG1 performed a specific exercise program at home during 8 weeks, and IG2 additionally used microcurrents on the abdominal region before the exercise program. All groups were given health education sessions. Computed tomography was used to evaluate abdominal, subcutaneous and visceral fat, accelerometers to measure habitual physical activity and the semi-quantitative food frequency questionnaire for dietary intake.

\section{Results}

After 8 weeks, IG2 showed a significantly decrease in subcutaneous fat ( $p \leq 0.05)$ when compared to CG. Concerning visceral fat, both intervention groups showed a significant decrease in comparison to the CG ( $p \leq 0.05)$. No significant changes were found between groups on dietary intake and habitual physical activity, except for sedentary activity that decreased significantly for IG2 in comparison with CG $(p \leq 0.05)$. 


\section{Conclusion}

This specific home-based exercise program using microcurrent therapy for individuals with coronary artery disease showed improvements in visceral and subcutaneous abdominal fat.

\section{Keywords}

Microcurrent; Exercise program; Cardiac rehabilitation

\section{Introduction}

Cardiovascular diseases (CVD) are considered to be the primary cause of death worldwide [1]. World Health Organization predicts more than 23.3 million deaths per year from CVD by 2030 [1].

Cardiovascular rehabilitation (CR) programs involve specific components such as education, counseling, behavior changes and physical exercise, in order to stimulate an active lifestyle and decrease cardiovascular risks [2] and [3]. Implementing home-based programs seems to improve adherence by overcoming some of the causes for their underuse [4] and [5].

A sedentary lifestyle associated with inappropriate food intake and has an impact on energetic balance contributing to overweight [6] and [7].

The larger number of fat cells in the abdominal region increases metabolic complications [8] and [9]. This association seems to be due to a higher lipolytic rate in the visceral and deep subcutaneous adipose tissue, promoting an increase of free fatty acids (FA) in the blood circulation [10], [11] and [12], and an increase in the hepatic synthesis of triglycerides, which translates into dyslipidemia [13]. Additionally, the adipose tissue plays an important role in the development of a systemic inflammatory state, by secreting several cytokines and chemokines [14] and [15]. This makes abdominal obesity a therapeutic target for CVD's patients.

Electrolipolysis techniques, using low frequency microcurrents and microamperes, are an innovative and effective method to help the lipolysis in a localized abdominal adipose tissue. The lipolysis effect by microcurrent is explained by an increase of adenosine triphosphate-ATP production, amino acid transport, and protein synthesis [16],[17] and [18] which promotes an increase of catecholamines' concentration, and consequently the activation of triglyceride lipase and hormone-sensitive lipase enzymes[19]. In addition, a thermal effect increases the blood flow and metabolism changes in membrane 
polarity, causing an increase of organelles' numbers responsible for cellular activities [16].

After triglyceride lipolysis into FA and glycerol, FA combines with albumin to create a free FA that can be used as energy source during physical exercise [13] and [20].

The application of this new electrolytic tool in conjunction with home-based exercise program aims to interfere directly in some cardiovascular risk factors, such as physical inactivity and obesity with android pattern. Such combination may promote greater health gains, minimizing the cardiovascular risks, in these populations [6], [7] and [21]. In this sense, the present study aims to investigate the effects of microcurrents and a home-based exercise program on total, subcutaneous and visceral abdominal adipose tissue in patients with coronary artery disease.

\section{Methods}

\subsection{Study design, randomization, and implementation}

This is a pilot and feasibility study investigating in a single center, and using a parallel-group, randomized controlled trial over 16 months. The participants, subjects with known coronary artery disease after one year of hospitalization for acute myocardial infarction (MI), were recruited at the cardiology outpatient service of a central hospital.

The study design is depicted in Fig. 1. Briefly, patients were invited to participate in the study and come to the cardiology outpatient service twice: once at the beginning of the study, initial moment (M0); and 2 months later, final moment (M1). At M0, participants were randomly assigned to one of three groups: Intervention Group 1 (IG1), which performed a specific exercise program at home; Intervention Group 2 (IG2) which underwent microcurrent application and the exercise program; and the Control Group (CG), which received usual medical care and follow-up. A randomization by blocks was used, and an allocation sequence based on a fixed block size of 3 was generated with a computer random number generator by an investigator not involved in the trial. All groups were provided with education sessions about Mediterranean diet and smoking cessation. At M0 and M1 each participant underwent several evaluations in the same sequence and at the same period of the day, the latter to avoid bias due to circadian rhythms. 


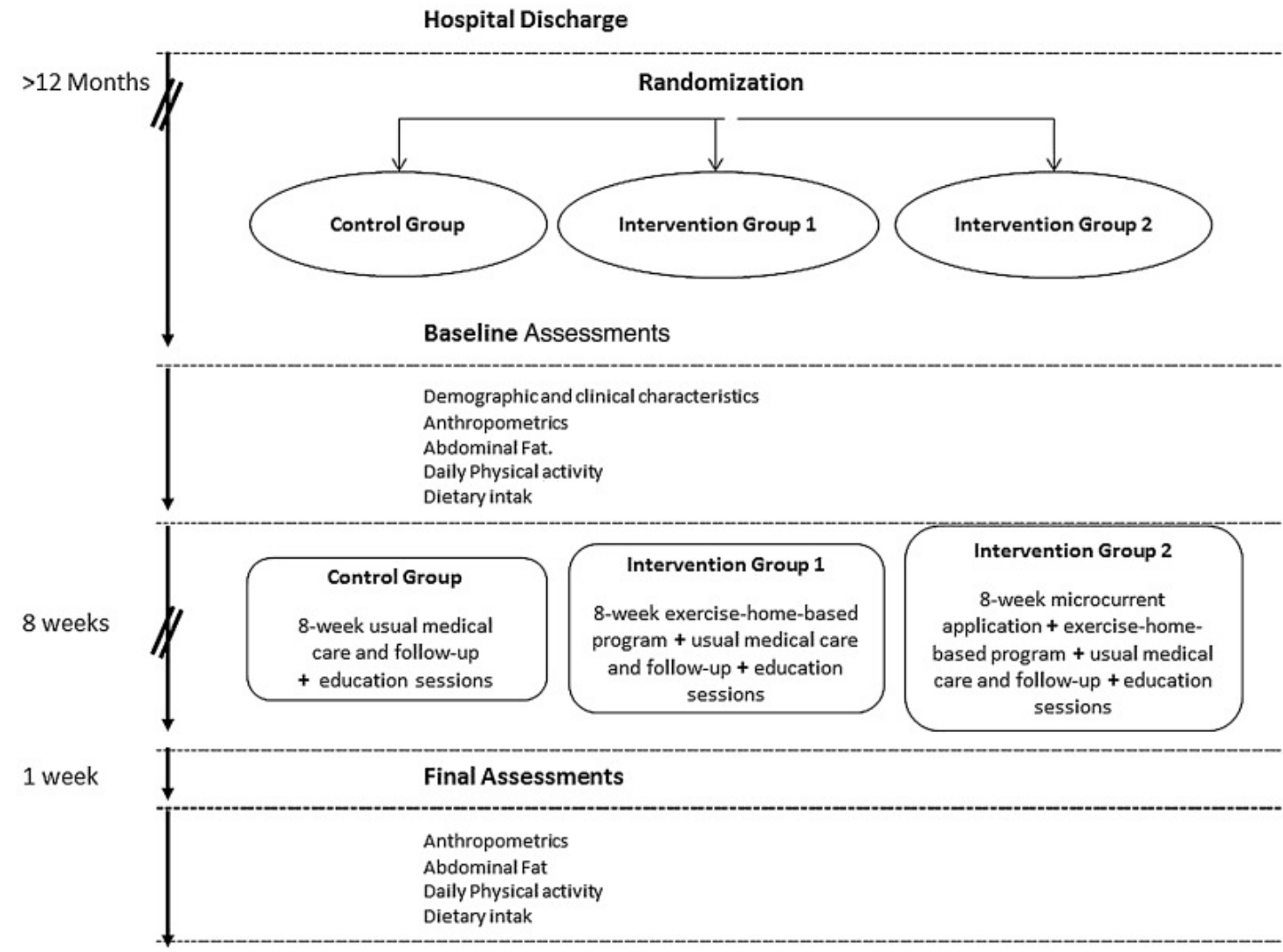

Fig. 1.

Study design (figure hospital discharge).

The enrollment and assignment was conducted by a cardiologist aware of the study design. Because exercise training and microcurrent therapy composed the intervention, the investigators implementing the intervention were not blind. However, the outcomes were analyzed by blind examiners.

This study was approved by the central hospital Ethics Commission (166/2011); all the procedures were conducted according to the Declaration of Helsinki, and the trial was registered at ClinicalTrials.gov (NCT01887080).

\subsection{Participants}

The patients were individually invited to participate in this study according to the inclusion/exclusion criteria. Eligible patients were those aged 40-75 years, men and women, referred to the Hospital Cardiology Department 1 year after an acute $\mathrm{MI}$ and with Montreal cognitive assessment $(\mathrm{MoCA}) \geq 26$. Exclusion criteria included the presence of left ventricle ejection fraction $<40 \%$, heart failure New York Heart Association Functional Classification-NYHA $\geq$ II, valvular heart disease, heart transplantation, congenital cardiopathy, hypertrophic cardiomyopathy, complex ventricular arrhythmias in the last 12 months, abnormal 
hemodynamic responses in the exercise test, incapacitating orthopedic, neurologic and/or peripheral vascular conditions, respiratory and cancer conditions, uncontrolled metabolic disease, any programmed or urgent interventions that could limit participation in the study and lack of attendance $<65 \%$.

We assessed 75 patients for eligibility and 53 complied with the criteria to participate in the study and were randomly assigned to the IG1, 18 participants, the IG2, 17 participants, and the CG, 18 participants (Fig. 2). Two subjects in the CG, 2 subjects in the IG1 and 5 in the IG2 were excluded from the study for lack of attendance and other complications. Thus, at the end of the study, the CG and the IG1 included 16 subjects each, and IG2 included 12 subjects.

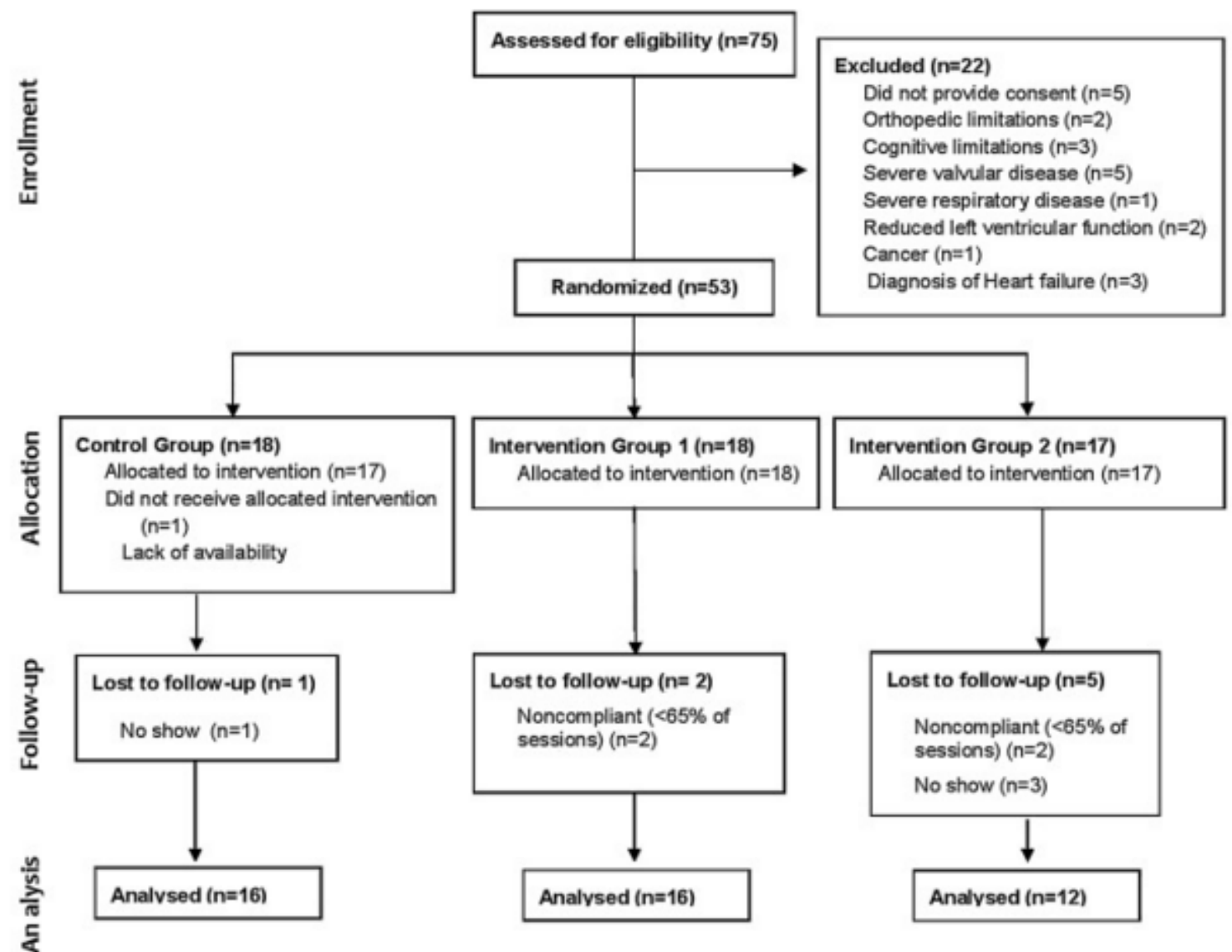

Fig. 2.

Flow diagram patients (assessed for eligbility $(n=75)$. 


\subsection{Measurements}

\subsubsection{Demographic and clinical characteristics}

Each potential subject completed a sample selection questionnaire to ensure compliance with inclusion/exclusion criteria. The MoCA questionnaire [22] was used for cognitive screening in order to ensure that the subjects were capable of understanding the study details, and safely use both the microcurrents and home exercise program [22].

\subsubsection{Anthropometrics}

Height was measured using a SECA ${ }^{\oplus}$-model 222 stadiometer (SECA—Medical Scales and Measuring Systems ${ }^{\circledR}$, Birmingham, United Kingdom) with an accuracy of $1 \mathrm{~mm}$. Body weight and fat percentage were evaluated using a Tanita ${ }^{\circledR}$ InnerScan model TBF-300A bioimpedance scale (based in 2625 South Clearbrook Drive, Arlington Heights, Illinois 60005, USA). Body mass index (BMI) was calculated by weight $(\mathrm{kg}) /$ square of height (meters). Waist circumference was measured at the midpoint between the lowest rib and the iliac crest with a flexible measure tape [23].

\subsubsection{Abdominal fat}

Abdominal adipose tissue was evaluated by computed tomography (TC) (SOMATOM Sensation ${ }^{\circledR} 64$; Siemens, Erlangen, Germany), using a $5 \mathrm{~mm}$ cut at the L4-L5 level[24] and [25], with exposure around $0.06 \mathrm{mSv}$ and attenuation values between -150 and -50 Hounsfield units [26].

\subsubsection{Daily physical activity}

Accelerometers (ActiGraph ${ }^{\circledast}$ GT3X, Pensacola, FL, USA) were used for seven consecutive days to obtain a picture of the habitual daily physical activity level. Subjects were instructed to place the accelerometer on the waist during the day, except while sleeping, bathing, and during aquatic activities. The Actilife software (Actilife v.6.11.2@ 2014 Actigraph $^{\oplus}$, LLC) was used to reduce the raw activity data from the accelerometers into daily physical activity. The average minutes per day spent at different physical activity intensities were determined according to cut points relating counts per minute to physical activity intensity [27] and [28].

\subsubsection{Dietary intake}

Semi-quantitative food frequency questionnaire (FFQ) [29] was applied in order to check the total fat (kcal), saturated fat (kcal), monounsaturated fat (kcal), 
polyunsaturated fat (kcal), carbohydrates (kcal) proteins (kcal), dietary fiber $(\mathrm{g})$, cholesterol (mg), alcohol (g) and calories (kcal) used by the participants [29]. The Food Processor Plus ${ }^{\circledast}$ (ESHA Research, Salem, Oregon) was used to convert food into nutrient.

\subsection{Interventions}

\subsubsection{Microcurrent therapy}

Microcurrents were applied using a portable electrostimulation device Trio ${ }^{\circledR} 300$ (Toyotama-Minami, Nerima-ku, Tokyo 176-0014, Japan), with a low frequency, bipolar square-wave alternating current. IG2 subjects were taught how to use the microcurrents device prior to beginning the exercise program. Four transcutaneous electrodes were used, with electrodes displayed in parallel on the abdominal region. The microcurrent program was completed 3 times per week for 2 months, before physical exercise. Each electrolipolysis session had a duration of $30 \mathrm{~min}$ : the first $15 \mathrm{~min}$ with a frequency of $30 \mathrm{~Hz}$ and the last $15 \mathrm{~min}$ with a frequency of $10 \mathrm{~Hz}$ (to prevent adipocyte desensitization) and an intensity below each subject's threshold of sensitivity (with a maximum limit of $750 \mu \mathrm{A})[30]$.

\subsubsection{Exercise training program}

A Polar ${ }^{\otimes}$ R300X heart rate monitor (Kempele, Finland) was used to monitor to the individual session in which exercise was prescribed and explained. Borg's scale of perceived exertion (6-20) was used to evaluate the level of exertion perceived by the subjects [31]. In the first session the participants were instructed in all aspects of the protocol including being taught how to use the Borg scale and measure of manual cardiac frequency. The exercise protocol (Table 1) consisted of 10 exercises, organized according to the following phases: warm up, workout and cool down [21] and [32]. The protocol was initiated at $60 \%$ of the maximum heart rate (MaxHR) by the exercise stress test in order to achieve a moderate intensity workout. The CR home program lasted 2 months, with a weekly frequency of 3 times. Exercise progression occurred after 4 weeks, reaching $70 \%$ MaxHR by adding one series and/or modifying the conditioning exercises. The number of repeats was adjusted to each subject during fortnight supervision [32] and [33]. This program was monitored by weekly remote supervision, using text messages, telephone calls or e-mail messages, and by fortnightly meetings to address any questions. 
Table 1.

Organization and explanation of the exercise protocol.

\begin{tabular}{|c|c|c|}
\hline Phase & Exercises & Explanation \\
\hline \multirow[t]{2}{*}{$\begin{array}{l}\text { Warm up } \\
(13 \mathrm{~min})\end{array}$} & $\begin{array}{l}\text { Walking in } \\
\text { place }\end{array}$ & $\begin{array}{l}\text { Hip flexion with flexion of the contralateral glenohumeral joint, } \\
\text { always in the same place }\end{array}$ \\
\hline & $\begin{array}{l}\text { Spine } \\
\text { rotation } \\
\text { (15 } \\
\text { repetitions) }\end{array}$ & $\begin{array}{l}\text { Hands at waist level, rotate the trunk (approximately } 90^{\circ} \text { ) in both } \\
\text { directions }\end{array}$ \\
\hline \multirow[t]{4}{*}{$\begin{array}{l}\text { Workout-strength } \\
\text { (15-20 min) } \\
\text { (repetitions } \\
\text { calculated by } \\
60-70 \% \text { MaxHR } \\
\text { to each } \\
\text { individual) }\end{array}$} & Crossing & $\begin{array}{l}\text { Keep walking in place throughout the exercise; perform the 1st } \\
\text { proprioceptive neuromuscular facilitation diagonal for bilateral upper } \\
\text { limb flexion (glenohumeral flexion, adduction and external rotation). } \\
\text { After } 4 \text { weeks perform the } 2 \text { nd proprioceptive neuromuscular } \\
\text { facilitation diagonal for bilateral upper limb flexion (glenohumeral } \\
\text { flexion, abduction and external rotation) }\end{array}$ \\
\hline & $\begin{array}{l}\text { Ankle } \\
\text { motion }\end{array}$ & $\begin{array}{l}\text { Dorsiflexion/plantar flexion of the ankles while sitting. After } 4 \text { weeks } \\
\text { perform while standing }\end{array}$ \\
\hline & $\begin{array}{l}\text { Backward } \\
\text { movements } \\
\text { of the arms }\end{array}$ & $\begin{array}{l}\text { Keep walking in place throughout the exercise; perform extension, } \\
\text { abduction and external rotation of the glenohumeral for the } \\
\text { complete range. At the end of the movement forc efully increase } \\
\text { range of motion } 10 \text { times }\end{array}$ \\
\hline & $\begin{array}{l}\text { Sit and } \\
\text { stand }\end{array}$ & $\begin{array}{l}\text { Sitting in a chair without leaning on the backrest, with upper limbs } \\
\text { crossed over the chest, the subject rises until maximum pelvic } \\
\text { anteversion is reached. Sitting should be performed in a controlled } \\
\text { movement }\end{array}$ \\
\hline \multirow{2}{*}{$\begin{array}{l}\text { Workout- } \\
\text { endurance } \\
\text { ( } 35-45 \mathrm{~min} \text { ) } \\
\text { (repetitions } \\
\text { calculated by } \\
60-70 \% \text { MaxHR } \\
\text { to each } \\
\text { individual) }\end{array}$} & $\begin{array}{l}\text { Step } \\
\text { forward, } \\
\text { sideways } \\
\text { and } \\
\text { backward }\end{array}$ & $\begin{array}{l}\text { Perform forward and backward half-step with bilateral upper limb } \\
\text { flexion, and sideways half-step with bilateral upper limb abduction } \\
\text { and lateral rotation }\end{array}$ \\
\hline & $\begin{array}{l}\text { Walk } \\
(30 \mathrm{~min})\end{array}$ & Perform at the subject's own pace \\
\hline \multirow{2}{*}{$\begin{array}{l}\text { Stretching } \\
(6 \text { min })(4 \\
\text { repetitions/ } \\
\text { maintain } 15 \mathrm{~s})\end{array}$} & $\begin{array}{l}\text { Calf muscle } \\
\text { stretching }\end{array}$ & Stretch the triceps surae \\
\hline & $\begin{array}{l}\text { Anterior } \\
\text { forearm } \\
\text { muscle } \\
\text { stretching }\end{array}$ & Stretch the wrist flexors \\
\hline
\end{tabular}

\subsection{Sample size calculation and statistical analysis}

The power calculation was computed a priori based in the results obtained in a pilot study conducted in 9 individuals, subject to the criteria for inclusion/exclusion 
previously define, that revealed a training effect (home exercise + microcurrent) of 0.6 on visceral fat. Assuming a power of $90 \%$ with a $5 \%$ significance level revealed a need for 39 patients to ensure statistical power to detect differences between the 3 groups in the variable difference (M1-M0). A target of patients 51 was identified to accommodate a maximal dropout rate of $25 \%$. This high dropout rate was conservatively anticipated due to the novelty of the intervention.

Statistical analysis was performed using the PASW Statistics 20 software (SPSS $\odot$ IBM Corporation, Route 100) for Windows $7^{\oplus}$, with a significance level of 0.05 and a confidence interval of $95 \%$. Normal data distribution was verified by Shapiro-Wilk test. Data was not normal distributed. Sample characterization was performed through descriptive statistics using median as measure of central tendency and interquartile range as measure of dispersion. In the intergroup analysis the Kruskal-Wallis test and the post-hoc Dunn test were used to compare the 3 groups in the initial (M0) and final (M1) moments and the variable difference (M1-M0). To compare the M0 and $\mathrm{M} 1$ were used the Wilcoxon tests.

\section{Results}

From 75 patients assessed for eligibility, 53 were recruited and agreed to participate in the study being randomized to the IG1, IG2 or CG. Nonetheless, only 44 ( 35 males and 9 females) were included in the analysis.

At baseline, no significant differences were observed between the three groups in demographic, clinical characteristics and medication (Table 2). The most frequent cardiovascular disease risk factors were hypertension and dyslipidemia, $100 \%$ present in all three groups. Most of the participants were taking antiplatelet agents, statins, beta-adrenergic blockers and angiotensin converting enzyme inhibitors. During the study the medication remained unchanged. 


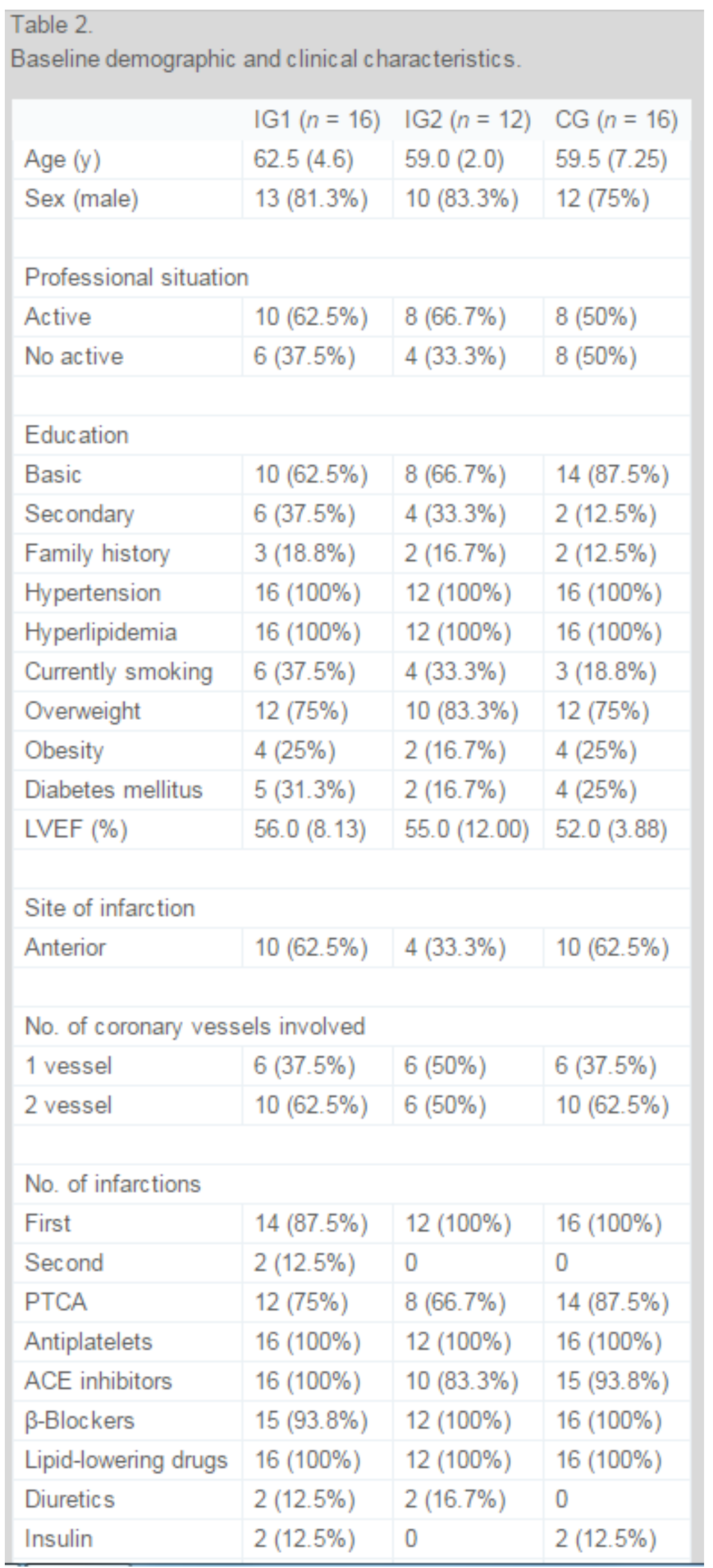


$\begin{array}{llll}\text { Antidiabetic agents } & 4(25 \%) & 1(8.3 \%) & 2(12.5 \%)\end{array}$

Data are expressed as median (Md) and interquartile range (IQR) or $n(\%)$. Criteria for diabetes are based on fasting blood gluc ose level $>125 \mathrm{mg} / \mathrm{dL}$ or current treatment with insulin or oral antidiabetic agents;

hypertension, based on seated blood pressure $>140 / 90 \mathrm{~mm} \mathrm{Hg}$ or antihypertensive treatment; overweight, based on body mass index $(\mathrm{BMI}) \geq 25<30 \mathrm{~kg} / \mathrm{m}^{2}$; obesity, based on $\mathrm{BMI} \geq 30 \mathrm{~kg} / \mathrm{m}^{2}$; and hyperlipidemia, based on fasting total cholesterol $>175 \mathrm{mg} / \mathrm{dL}$ or use of antidislipidemic medic ation.

Abbreviations: ACE, angiotensin-converting enzyme; ARB, angiotensin II receptor blocker, HDL, highdensity lipoprotein; LDL, low-density lipoprotein; LVEF, left ventric ular ejection fraction; PTCA, percutaneous transluminal coronary angioplasty.

At baseline the 3 groups were similar concerning anthropometrics, abdominal fat, daily physical activity and dietary intake measurements $(p>0.05)$.

From M0 to M1, a significant decrease in fat percentage was found in IG1 $(p=0.011)$ and IG2 $(p=0.026)$ (Table 3$)$.

Table 3.

Changes in anthropometrics.

\begin{tabular}{|c|c|c|c|c|c|c|c|c|}
\hline & \multicolumn{6}{|c|}{ Md (IQR) } & \multirow{3}{*}{$p^{a}$} & \multirow{3}{*}{$p^{\mathrm{b}}$} \\
\hline & \multicolumn{2}{|c|}{ IG1 $(n=16)$} & \multicolumn{2}{|c|}{ IG2 $(n=12)$} & \multicolumn{2}{|c|}{$\mathrm{CG}(n=16)$} & & \\
\hline & MO & M1 & MO & M1 & MO & M1 & & \\
\hline \multirow[t]{2}{*}{ Height (cm) } & 163.5 & - & 168.0 & - & 163.5 & - & - & - \\
\hline & $(7.0)$ & & $(2.0)$ & & $(8.1)$ & & & \\
\hline \multirow[t]{2}{*}{ Body mass (kg) } & 75.0 & 73.7 & 76.5 & 75.2 & 74.9 & 77.1 & 0.759 & 0.019 \\
\hline & $(11.4)$ & $(10.9)$ & $(9.5)$ & $(8.8)$ & $(14.2)$ & $(16.7)$ & & $\begin{array}{l}\mathrm{GE} 1<\mathrm{GC} \\
\left(p^{\mathrm{C}}=0.006\right)\end{array}$ \\
\hline \multirow[t]{2}{*}{$\mathrm{BMI}\left(\mathrm{kg} / \mathrm{m}^{2}\right)$} & 28.4 & 28.0 & 27.8 & 27.6 & 27.6 & 28.1 & 0.476 & 0.013 \\
\hline & (2.6) & $(2.4)$ & $(1.8)$ & $(1.9)$ & $(4.6)$ & $(4.6)$ & & $\begin{array}{l}\mathrm{GE} 1<\mathrm{GC} \\
\left(p^{\mathrm{C}}=0.008\right)\end{array}$ \\
\hline \multirow[t]{2}{*}{ Fat percentage $(\%)$} & 28.6 & 26.5 & 29.7 & 29.25 & 30.6 & 30.2 & \multirow[t]{2}{*}{0.948} & \multirow[t]{2}{*}{0.121} \\
\hline & $(5.3)$ & $(4.7)$ & $(5.2)$ & $(6.5)$ & (3.2) & (2.9) & & \\
\hline \multirow{2}{*}{$\begin{array}{l}\text { Waist circumference } \\
\text { (cm) }\end{array}$} & 100.6 & 98.8 & 98.8 & 99.5 & 100.7 & 101.9 & \multirow[t]{2}{*}{0.735} & \multirow[t]{2}{*}{0.220} \\
\hline & $(5.8)$ & (7.9) & (7.7) & $(7.00)$ & $(9.1)$ & (8.3) & & \\
\hline
\end{tabular}

Data are expressed as median (Md) and interquartile range (IQR).

a $p$ value for final moment (M1) with Kruskal-Wallis test.

b $p$ value for the variable difference (M1-M0) with Kruskal-Wallis test.

c $p$ value for Dunn post-hoc test. 
In anthropometrics measurements after 8 weeks of intervention significant differences were found between the 3 groups for the variable difference (M1-M0) of body mass and BMI, with a significant decrease in IG1 when compared to CG ( $p=0.008$ and $p=0.013$, respectively) (Table 3 ).

After 8 weeks of intervention there was a significant decrease in subcutaneous fat in IG2 ( $p=0.036)$.

Regarding total fat there was no significant differences between the 3 groups at the end of the study. After 8 weeks there were observed significant differences between groups for subcutaneous fat, with a significant decrease in IG2 when compared to the CG $(p=0.005)$. Concerning visceral fat, both intervention groups showed a significant decrease in comparison to the CG ( $p=0.038$ and $p=0.029$, respectively) (Table 4 ).

Table 4.

Changes in abdominal fat.

\begin{tabular}{|c|c|c|c|c|c|c|c|c|}
\hline & \multicolumn{6}{|c|}{ Md (IQR) } & \multirow{3}{*}{$p^{\mathrm{a}}$} & \multirow{3}{*}{$p^{\mathrm{b}}$} \\
\hline & \multicolumn{2}{|c|}{ IG1 $(n=16)$} & \multicolumn{2}{|c|}{ IG2 $(n=12)$} & \multicolumn{2}{|c|}{$\operatorname{CG}(n=16)$} & & \\
\hline & MO & M1 & MO & M1 & MO & M1 & & \\
\hline \multirow{2}{*}{$\begin{array}{l}\text { Subcutaneous fat } \\
\left(\mathrm{cm}^{2}\right)\end{array}$} & 206.5 & 172.0 & 157.0 & 116.0 & 178.5 & 216.5 & 0.211 & 0.018 \\
\hline & (54.9) & $(53.1)$ & (53.5) & $(80.1)$ & (62.2) & $(64.0)$ & & $\begin{array}{l}\mathrm{GE} 2<\mathrm{GC} \\
\left(p^{\mathrm{C}}=0.005\right)\end{array}$ \\
\hline \multirow[t]{2}{*}{ Visceral fat $\left(\mathrm{cm}^{2}\right)$} & 130.5 & 123.0 & 124.5 & 109.0 & 158.5 & 154.0 & 0.042 & 0.435 \\
\hline & $(47.9)$ & $(40.3)$ & $(80.5)$ & $(56.4)$ & $(15.6)$ & $(29.6)$ & $\begin{array}{l}\mathrm{GE} 2<\mathrm{GC} \\
\left(p^{\circ}=0.029\right) \\
\mathrm{GE} 1<\mathrm{GC} \\
\left(p^{\circ}=0.038\right)\end{array}$ & \\
\hline \multirow[t]{2}{*}{ Total fat $\left(\mathrm{cm}^{2}\right)$} & 329.5 & 310.5 & 379.0 & 345.0 & 329.0 & 361.0 & 0.519 & 0.121 \\
\hline & $(48.8)$ & (75.1) & $(97.5)$ & (114.5) & (78.3) & $(92.0)$ & & \\
\hline
\end{tabular}

Data are expressed as median (Md) and interquartile range (IQR).

a $p$ value for final moment (M1) with Kruskal-Wallis test.

b $p$ value for the variable difference (M1-M0) with Kruskal-Wallis test.

c $p$ value for Dunn post-hoc test.

In CG from M0 to M1 assessment, there was a significant increase in sedentary PA $(p=0.005)$. 
Also after the intervention no significant differences were observed in habitual physical activity, except for sedentary activity that decreased significantly for IG2 in comparison with CG ( $p=0.007)$ (Table 5).

Table 5 .

Changes in daily PA.

\begin{tabular}{|c|c|c|c|c|c|c|c|c|}
\hline & \multicolumn{6}{|l|}{ Md (IQR) } & \multirow{3}{*}{$p^{\mathrm{a}}$} & \multirow{3}{*}{$p^{\mathrm{b}}$} \\
\hline & \multicolumn{2}{|c|}{ IG1 $(n=14)$} & \multicolumn{2}{|c|}{ IG2 $(n=12)$} & \multicolumn{2}{|c|}{ CG $(n=15)$} & & \\
\hline & MO & M1 & MO & M1 & MO & M1 & & \\
\hline \multirow{2}{*}{$\begin{array}{l}\text { Total PA } \\
\text { (counts/min) }\end{array}$} & 318.80 & 343.84 & 407.60 & 381.84 & 333.37 & 301.63 & 0.237 & 0.576 \\
\hline & $(136.69)$ & $(158.17)$ & $(116.40)$ & $(42.60)$ & $(115.59)$ & $(87.19)$ & & \\
\hline \multirow{2}{*}{$\begin{array}{l}\text { Sedentary PA } \\
\text { (min/day) }\end{array}$} & 647.64 & 582.65 & 573.13 & 537.52 & 607.96 & 717.93 & 0.004 & 0.025 \\
\hline & $(123.09)$ & $(100.75)$ & $(50.85)$ & $(27.76)$ & $(52.36)$ & $(68.45)$ & $\begin{array}{l}\text { GE2 }<\text { GC } \\
p^{c}=(0.001)\end{array}$ & $\begin{array}{l}\text { GE2 }<\text { GC } \\
p^{c}=(0.007)\end{array}$ \\
\hline \multirow{2}{*}{$\begin{array}{l}\text { Light PA } \\
\text { (min/day) }\end{array}$} & 172.15 & 194.44 & 174.68 & 199.40 & 135.77 & 175.21 & 0.165 & 0.541 \\
\hline & $(62.92)$ & $(38.17)$ & $(8.97)$ & $(49.05)$ & $(41.55)$ & $(19.75)$ & & \\
\hline \multirow{2}{*}{$\begin{array}{l}\text { MVPA } \\
\text { (min/day) }\end{array}$} & 45.25 & 55.12 & 55.08 & 50.59 & 49.08 & 49.31 & 0.833 & 0.094 \\
\hline & $(21.66)$ & (31.34) & $(15.85)$ & (16.03) & $(28.02)$ & (15.61) & & \\
\hline
\end{tabular}

Abbreviations: PA, physical activity; MVPA, moderate to vigorous physical activity.

Data are expressed as median (Md) and interquartile range (IQR).

a p value for final moment (M1) with Kruskal-Wallis test.

b $p$ value for the variable difference (M1-M0) with Kruskal-Wallis test.

c $p$ value for Dunn post-hoc test.

Concerning dietary intake, no significant changes in nutrients intake were observed between groups at M1 and M1-M0 (Table 6). 
Table 6.

Changes in dietary intake.

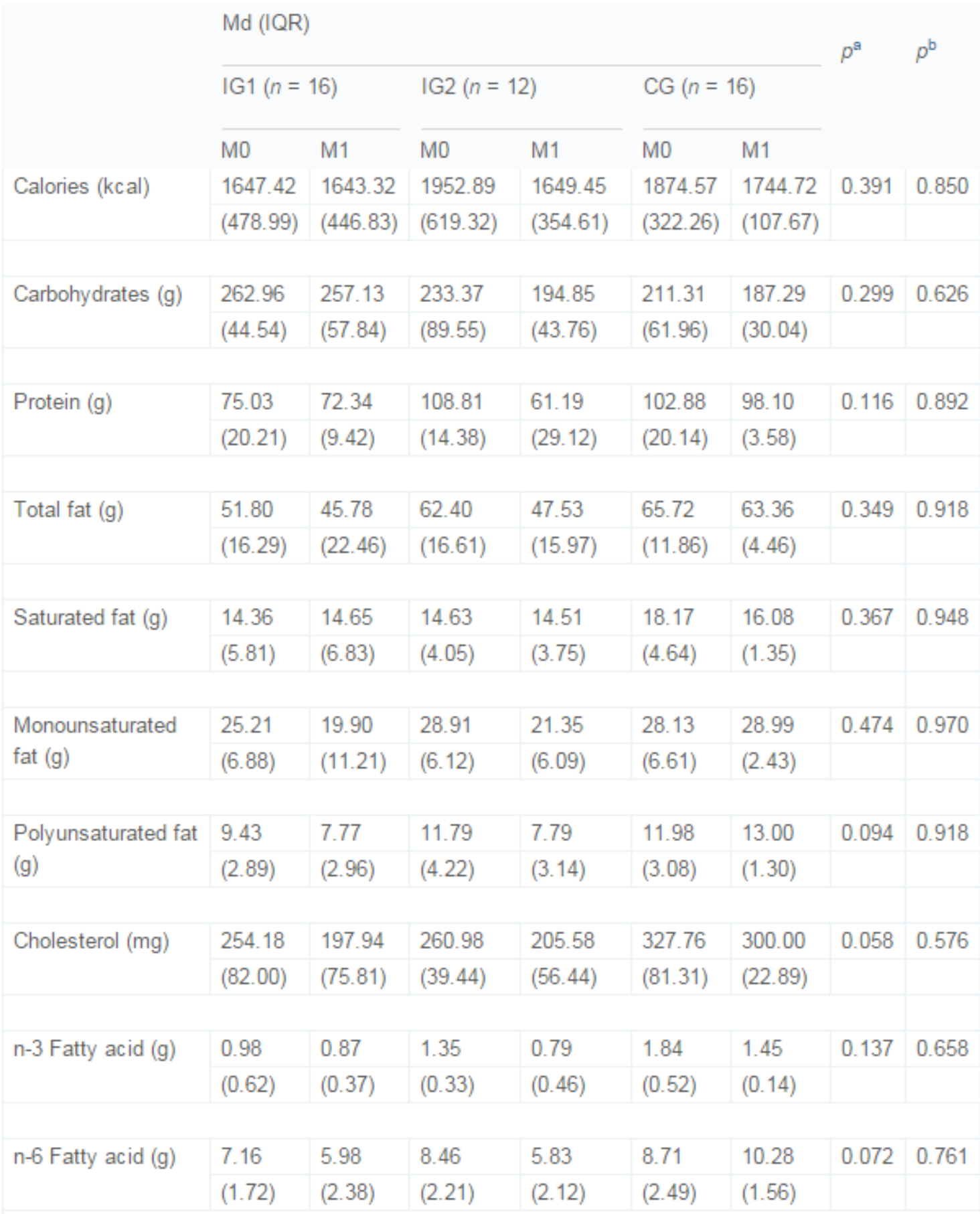




\begin{tabular}{|l|l|l|l|l|l|l|l|l|}
\hline Total fiber (g) & 24.66 & 26.86 & 30.97 & 23.63 & 23.95 & 19.78 & 0.512 & 0.295 \\
\hline & $(7.33)$ & $(5.87)$ & $(12.79)$ & $(5.13)$ & $(5.52)$ & $(3.96)$ & & \\
\hline \multirow{2}{*}{ Sugars (g) } & 139.33 & 114.48 & 104.03 & 75.35 & 78.03 & 73.28 & 0.184 & 0.441 \\
\hline & $(18.12)$ & $(23.67)$ & $(42.04)$ & $(12.88)$ & $(27.23)$ & $(10.49)$ & & \\
\hline & 1.59 & 3.40 & 5.93 & 4.97 & 8.77 & 4.97 & 0.939 & 0.553 \\
\hline Alcohol (g) & $(11.37)$ & $(10.44)$ & $(15.02)$ & $(2.49)$ & $(14.5)$ & $(14.72)$ & & \\
\hline & 1148.79 & 709.30 & 917.09 & 792.16 & 870.35 & 730.40 & 0.576 & 0.446 \\
\hline Calcium (mg) & $(310.07)$ & $(178.08)$ & $(631.84)$ & $(76.03)$ & $(59.69)$ & $(56.62)$ & & \\
\hline & 2980.82 & 2979.44 & 3517.41 & 2852.87 & 3496.49 & 3485.95 & 0.347 & 0.195 \\
\hline Sodium (g) & $(982.71)$ & $(765.25)$ & $(1121.20)$ & $(1004.79)$ & $(964.15)$ & $(280.38)$ & & \\
\hline & 45.05 & 39.83 & 24.19 & 10.60 & 32.13 & 35.86 & 0.064 & 0.052 \\
\hline Caffeine (mg) & $(13.86)$ & $(24.06)$ & $(29.10)$ & $(14.51)$ & $(17.06)$ & $(15.31)$ & & \\
\hline
\end{tabular}

In CG from M0 to M1 assessment, there was a significant decrease in saturated fat $(p=0.012)$, cholesterol $(p=0.036)$ and total fiber $(p=0.036)$. In IG1 from baseline to M1 assessment, there was a significant decrease in n3 FA $(p=0.003)$, sugars $(P=0.036)$, calcium $(p=0.012)$.

\section{Discussion}

The MI participants were chosen as cardiovascular risk factors were present as well as the fact that they were sedentary and overweight.

Cytokines production and other pro-inflammatory markers are related with the increase in visceral fat and are determinants for atherosclerosis [3], [4], [5], [6], [7], [8], [9], [10],[11], [12], [13], [14], [15], [16], [17 ], [18], [19], [20], [21], [22], [23], [24], [25], [26], [27], [28],[29], [30], [31], [32], [33 ], [34], [35] and [36]. Central obesity seems to be directly related to insulin resistance and to systemic inflammation that in turn increase the risk of metabolic syndrome and CVD [36]. So the negative impact of fat in increasing insulin sensitivity is clearly shown as evidence for the positive impact of the physical exercise and/or loss of weight [36] and [37].

This specific home-based exercise program (IG1 and IG2) showed a decrease in visceral fat in individuals with coronary artery disease, although only the use of 
both microcurrent and the exercise protocol (IG2) significantly decreased subcutaneous fat, as measured by computed tomography.

In fact, and according to Ref. [38] electro-stimulation promotes changes in cells' structure and behavior, by acting on voltage-dependent potassium channels, and on norepinephrine levels. The increase of catecholamines seems to induce a membrane depolarization, which raises intracellular levels of cyclic adenosine monophosphate, boosting the activation of protein kinase $A$ and lipolytic enzymes (hormone sensitive lipase and lipoprotein lipase) responsible for triglyceride degradation [13], [19],[20] and [39].

The decrease of subcutaneous abdominal fat could be an important achievement, as it increases the activation of deep subcutaneous adipocytes, which are larger in size and with high expression of pro-inflammatory, lipogenic and lipolytic genes and a high proportion of saturated FA, that can be compared to visceral fat in male [12]. Therefore, changes in this compartment seem to be due to a decrease in the size of subcutaneous fat cells which are related to cardiovascular risk reduction in subjects with coronary artery disease [12], [40] and [41].

After an application of microcurrents, a moderate intensity exercise $(60-70 \%$ of the maximum exercise stress test heart rate) uses the free FA for energy, and that can prolong the lipolysis, enhancing FA oxidation [42] and [43]. It has been demonstrated that the use of moderate intensity in prolonged exercise progressively increases the lipolytic rate, and $1 \mathrm{~h}$ after the end of the exercise a further increase in lipolysis occurs for approximately $3 \mathrm{~h}$ [44]. The results suggest that physical exercise after the application of microcurrents seems to have a greater effect in reducing subcutaneous abdominal fat when compared to exercise alone. It was suggested that the mobilization of triglycerides in subcutaneous adipose tissue promoted by physical activity seems to be associated with an increase in the concentration of atrial natriuretic peptide that promotes a strong lipid-mobilizing effect that is independent of the activation of the sympathetic nervous system [45].

Since the association of microcurrent and exercise seems to promote a greater reduction of subcutaneous fat mass in overweight individuals, as observed in this study, we can infer that the microcurrent induces a reduction in inflammation, and may even contribute to the decrease of insulin resistance. Thus, according to Ref. [46] microcurrent might be a useful therapy in complementary treatment of diabetes, HTA and chronic wounds. Mitochondria stabilization functioning as antioxidants, and therefore increasing the normal function of pancreatic $\beta$ cells and vascular tissue, contribute to a resistance to insulin's reduction [46]. However, it is important to note that physical exercise per se (without being 
accompanied by changes in fat mass), promotes an inflammation reduction and insulin resistance [37] and [47]. The improvement of insulin resistance with regular exercise in overweight or obese individuals is associated with improved hepatic insulin resistance, an increase in <beta> cell function of the pancreas and the secretion of adiponectin by fat tissue [37].

The reduction of visceral fat in the intervention groups (IG1 and IG2) compared with the CG demonstrates that the visceral adipose tissue is responsive to adrenergic activation by physical exercise, managing to promote lipolysis in visceral adipocytes [44].

Endurance and resistance exercises were used in this specific home-based program which demonstrated superior results for losing body fat, maintaining/increasing lean body mass, and improving the lipid profile in subjects with coronary artery disease [21] and [48]. In this study the IG1 reduced body fat and $\mathrm{BMI}$ in relation to $\mathrm{CG}$, and from baseline to $\mathrm{M1}$, both intervention groups significantly decreased fat percentage, confirming the generalized effects of physical exercise.

There were no significant results in reducing BMI in IG2; however, BMI is frequently used as an indicator of body fat. Nevertheless, its analysis does not allow a distinction between the composition of body fat and lean body mass, being the reason why TC was used in this study [23].

The exercise volume in this protocol was approximately 250 min per week, performed over 3 days, matching the conclusions in the systematic review [49]. The current guidelines of the American College of Sports Medicine recommend $150 \mathrm{~min}$ of moderate activity per week as sufficient for beneficial effects on abdominal fat [48] and [49]. One randomized control trial [50] showed that the loss of visceral fat is associated with a high volume of training (15-20 h per week) over a long period of time [50]. However, in this study there was a significant loss of visceral fat in both intervention groups; nonetheless, the reduction was not greater in the microcurrent protocol when compared with only exercise protocol. Nevertheless, a study similar to the present, but in healthy subjects, found a significant reduction in visceral fat due to microcurrent [39]. One possible explanation would be the beta-blockers taken by the subjects, given that their mechanism of action is based on competition with endogenous catecholamines at the $\beta$-adrenergic receptor level [51], not allowing the activation of $\beta$-adrenergic by the effect of electrical current. This physiological process seems to induce a decrease in the sensitivity of this stimulation's route, and therefore can affect lipolysis in visceral adipocytes.

In this study, at baseline, the components of dietary intake were already in the current recommendations and did not change after 8 weeks for the IG2 which 
means that in this group the results were not influenced by changing eating habits [52], [53] and [54]. The IG1 and CG no differences were found between them at any moment; however, after 8 weeks, the IG1 and CG change some components of dietary intake, that show the effects of the education sessions about Mediterranean food.

The daily physical activity did not change for the total, moderated and vigorous activity, but sedentary activity decreased significantly in IG2 in comparison with CG. However, this result should be analyzed carefully, since the CG light increased the sedentary activity. Like dietary intake, the daily physical activity was already in the current recommendations [54].

In this study one subject could not be allocated in the program and 8 withdrawals occurred due to lack of attendance to the sessions; the main reason was due to economic costs of transportation to the hospital for bimonthly supervision and/or difficulties coping with professional duties. Intervention groups 1 and 2 adherence rate was about $65 \%$, the researchers have attempted to identify factors that influence program participation, and some social and demographic factors have been suggested. Younger, male, employed subjects with higher socio-economic status and higher education levels are more likely to take part in CR [55]. Withdrawals in IG2 can be explained by the difficulties in the application and handling of the device, as well as protocol's duration (8 weeks). Any side effects occurred in the groups. An additional limitation is the short duration of the CR program that might not be sufficient to more structural changes in the abdominal fat. Fat loss is more noticeable after one year of intervention at home [50].

This is small study and may not be representative. Further studies on the mechanisms and practical application of microcurrent in both men and women are now required.

\section{Conclusion}

This specific exercise program showed improvements in visceral fat in individuals with coronary artery disease. Microcurrent therapy associated with a home-based exercise program suggested a decreased in subcutaneous abdominal fat, as measured by computed tomography.

The use of microcurrent therapy on the abdominal region can be a way to support the exercise in CR programs, contributing to decreases in cardiovascular risk and metabolic diseases. 


\section{References}

[1]

WHO

Global Atlas On Cardiovascular Disease Prevention And Control

World Health Organization, Geneva (2011)

[2]

N.K. Wenger

Current status of cardiac rehabilitation

J. Am. Coll. Cardiol., 51 (2008), pp. 1619-1631

[3]

R.J. Thomas, M. King, K. Lui, N. Oldridge, I.L. Piña, J. Spertus, et al.

AACVPR/ACC/AHA 2007 performance measures on cardiac rehabilitation for referral to and delivery of cardiac rehabilitation/secondary prevention services endorsed by the American College of Chest Physicians, American College of Sports Medicine, American Physical Therapy Association, Canadian Association of Cardiac Rehabilitation, European Association for Cardiovascular Prevention and Rehabilitation, Inter-American Heart Foundation, National Association of Clinical Nurse Specialists, Preventive Cardiovascular Nurses Association, and the Society of Thoracic Surgeons J. Am. Coll. Cardiol., 50 (2007), pp. 1400-1433

[4]

J. Blair, H. Corrigall, N.J. Angus, D.R. Thompson, S. Leslie Home versus hospital-based cardiac rehabilitation: a systematic review Rural Remote Health, 11 (2011), p. 1532

[5]

G.J. Balady, M.A. Williams, P.A. Ades, V. Bittner, P. Comoss, J.M. Foody, et al. Core components of cardiac rehabilitation/secondary prevention programs:update: a scientific statement from the American Heart Association Exercise, Cardiac Rehabilitation, and Prevention Committee, the Council on Clinical Cardiology; the Councils on Cardiovascular Nursing, Epidemiology 
and Prevention, and Nutrition, Physical Activity, and Metabolism; and the American Association of Cardiovascular and Pulmonary Rehabilitation Circulation, 115 (2007), pp. 2675-2682

[6]

B. Strasser

Physical activity in obesity and metabolic syndrome

Ann. N. Y. Acad. Sci., 1281 (2012), pp. 141-159

[7]

T.A. Wadden, V.L. Webb, C.H. Moran, B.A. Bailer

Lifestyle modification for obesity: new developments in diet, physical activity, and behavior therapy

Circulation, 125 (2012), pp. 1157-1170

[8]

M.C. Amato, V. Guarnotta, C. Giordano

Body composition assessment for the definition of cardiometabolic risk

J. Endocrinol. Invest., 36 (2013), pp. 537-543

[9]

S.A. Westphal

Obesity, abdominal obesity, and insulin resistance

Clin. Cornerstone, 9 (2008), pp. 23-29

[10]

J. Liu, C.S. Fox, D.A. Hickson, W.D. May, K.G. Hairston, J.J. Carr, et al.

Impact of abdominal visceral and subcutaneous adipose tissue on cardiometabolic risk factors: the Jackson Heart Study

J. Clin. Endocrinol. Metab., 95 (2010), pp. 5419-5426 
C.S. Fox, J.M. Massaro, U. Hoffmann, K.M. Pou, P. Maurovich-Horvat, C.Y. Liu, et al.

Abdominal visceral and subcutaneous adipose tissue compartments: association with metabolic risk factors in the Framingham Heart Study

Circulation, 116 (2007), pp. 39-48

K. Marinou, L. Hodson, S.K. Vasan, B.A. Fielding, R. Banerjee, K. Brismar, et al. Structural and functional properties of deep abdominal subcutaneous adipose tissue explain its association with insulin resistance and cardiovascular risk in men

Diab. Care, 37 (2014), pp. 821-829

M. Ahmadian, Y. Wang, H.S. Sul

Lipolysis in adipocytes

Int. J. Biochem. Cell Biol., 42 (2010), pp. 555-559

[14]

P. Calabro, E.T. Yeh

Intra-abdominal adiposity, inflammation, and cardiovascular risk: new insight into global cardiometabolic risk

Curr. Hypertens. Rep., 10 (2008), pp. 32-38

I. Lemieux, A. Pascot, D. Prud'homme, N. Almeras, P. Bogaty, A. Nadeau, et al.

Elevated C-reactive protein: another component of the atherothrombotic profile of abdominal obesity

Arterioscler. Thromb. Vasc. Biol., 21 (2001), pp. 961-967

D. Curtis, S. Fallows, M. Morris, C. McMakin

The efficacy of frequency specific microcurrent therapy on delayed onset muscle soreness

J. Bodyw. Mov. Ther., 14 (2010), pp. 272-279 
[17]

N. Cheng, H. Van Hoof, E. Bockx, M.J. Hoogmartens, J.C. Mulier, F.J. De Dijcker, et al.

The effects of electric currents on ATP generation, protein synthesis, and membrane transport of rat skin

Clin. Orthop. Relat. Res. (1982), pp. 264-272

[18]

Y. Ohno, H. Fujiya, A. Goto, A. Nakamura, Y. Nishiura, T. Sugiura, et al.

Microcurrent electrical nerve stimulation facilitates regrowth of mouse soleus muscle

Int. J. Med. Sci., 10 (2013), pp. 1286-1294

[19]

I. de Glisezinski, D. Larrouy, M. Bajzova, K. Koppo, J. Polak, M. Berlan, et al.

Adrenaline but not noradrenaline is a determinant of exercise-induced lipid mobilization in human subcutaneous adipose tissue

J. Physiol., 587 (2009), pp. 3393-3404

[20]

A. Guyton, J. Hall

Medical Physiology

Sounders Elsevier, Philadelphia (2011)

[21]

ACSM

Guidelines For Exercise Testing And Prescription-american College of Sports Medicine

Wolters Kluwer/Lippincott Williams \& Wilkins Health (2013)

D. Duro, M.R. Simões, E. Ponciano, I. Santana

Validation studies of the Portuguese experimental version of the Montreal Cognitive Assessment (MoCA): confirmatory factor analysis 
J. Neurol., 257 (2010), pp. 728-734

[23]

R. Eston, T. Reilly

Kinanthropometry And Exercise Physiology Laboratory Manual: Tests, Procedures And Data

Taylor \& Francis (2009)

[24]

D. Berker, S. Koparal, S. Isik, L. Pasaoglu, Y. Aydin, K. Erol, et al.

Compatibility of different methods for the measurement of visceral fat in different body mass index strata

Diagn. Interv. Radiol., 16 (2010), pp. 99-105

[25]

R. Fontes-Carvalho, M. Fontes-Oliveira, F. Sampaio, J. Mancio, N. Bettencourt, M. Teixeira, et al.

Influence of epicardial and visceral fat on left ventricular diastolic and systolic functions in patients after myocardial infarction

Am. J. Cardiol., 114 (11) (2014), pp. 1663-1669

[26]

Siemens SOMATOM sensation 64-Application Guide (protocols, principles, helpful hints). 2007.

R.P. Troiano, D. Berrigan, K.W. Dodd, L.C. Masse, T. Tilert, M. McDowell

Physical activity in the United States measured by accelerometer

Med. Sci. Sports Exerc., 40 (2008), pp. 181-188

J. Oliveira, F. Ribeiro, H. Gomes

Effects of a home-based cardiac rehabilitation program on the physical activity levels of patients with coronary artery disease

J. Cardiopulm. Rehabil. Prev., 28 (2008), pp. 392-396 
[29]

C. Lopes, A. Aro, A. Azevedo, E. Ramos, H. Barros

Intake and adipose tissue composition of fatty acids and risk of myocardial infarction in a male Portuguese community sample

J. Am. Diet. Assoc., 107 (2007), pp. 276-286

[30]

A.S.C. Melo, J.S. Moreira, A. Noites, M.F. Couto, C. Argel Melo

Clay body wrap with microcurrent: effects in central adiposity

Appl. Clay Sci., 80-81 (2013), pp. 140-146

[31]

G. Borg

Ratings of perceived exertion and heart rates during short-term cycle exercise and their use in a new cycling strength test

Int. J. Sports Med., 3 (1982), pp. 153-158

[32]

ACPICR

Standards For Physical Activity And Exercise In The Cardiac Population

Association of Chartered Physiotherapists in Cardiac Rehabilitation (2009)

P.R. Lawler, K.B. Filion, M.J. Eisenberg

Efficacy of exercise-based cardiac rehabilitation post-myocardial infarction: a systematic review and meta-analysis of randomized controlled trials

Am. Heart J., 162 (2011), pp. 571-584.e2

[34]

C. Finelli, L. Sommella, S. Gioia, N. La Sala, G. Tarantino

Should visceral fat be reduced to increase longevity

Ageing Res. Rev., 12 (2013), pp. 996-1004 
[35]

A.S. Al-Goblan, M.A. Al-Alfi, M.Z. Khan

Mechanism linking diabetes mellitus and obesity

Diabetes Metab. Syndr. Obes., 7 (2014), pp. 587-591

[36]

A.H. Berg, P.E. Scherer

Adipose tissue, inflammation, and cardiovascular disease

Circ. Res., 96 (2005), pp. 939-949

[37]

R.K. Nelson, J.F. Horowitz

Acute exercise ameliorates differences in insulin resistance between physically active and sedentary overweight adults

Appl. Physiol. Nutr. Metab., 39 (2014), pp. 1-8

Z.H. Hamida, A.S. Comtois, M. Portmann, J.P. Boucher, R. Savard

Effect of electrical stimulation on lipolysis of human white adipocytes

Appl. Physiol. Nutr. Metab., 36 (2011), pp. 271-275

[39]

A. Noites, R. Nunes, A.I. Gouveia, A. Mota, C. Melo, A. Viera, et al.

Effects of aerobic exercise associated with abdominal microcurrent: a preliminary study

J. Altern. Complement. Med., 21 (2015), pp. 229-236

[40]

A. Tchernof, C. Belanger, A.S. Morisset, C. Richard, J. Mailloux, P. Laberge, et al. Regional differences in adipose tissue metabolism in women: minor effect of Diabetes, 55 (2006), pp. 1353-1360

T. You, K.M. Murphy, M.F. Lyles, J.L. Demons, L. Lenchik, B.J. Nicklas 
Addition of aerobic exercise to dietary weight loss preferentially reduces abdominal adipocyte size

Int. J. Obes., 30 (2006), pp. 1211-1216

[42]

J. Achten, A.E. Jeukendrup

Optimizing fat oxidation through exercise and diet

Nutrition, 20 (2004), pp. 716-727

C.E. Garber, B. Blissmer, M.R. Deschenes, B.A. Franklin, M.J. Lamonte, I.M. Lee, et al.

American College of Sports Medicine position stand. Quantity and quality of exercise for developing and maintaining cardiorespiratory, musculoskeletal, and neuromotor fitness in apparently healthy adults: guidance for prescribing exercise

Med. Sci. Sports Exerc., 43 (2011), pp. 1334-1359

[44]

D. Thompson, F. Karpe, M. Lafontan, K. Frayn

Physical activity and exercise in the regulation of human adipose tissue physiology

Physiol. Rev., 92 (2012), pp. 157-191

C. Moro, F. Pillard, I.D. Glisezinski, E. Klimcakova, F. Crampes, C. Thalamas, et al. Exercise-induced lipid mobilization in subcutaneous adipose tissue is mainly related to natriuretic peptides in overweight men

Am. J. Physiol. Endocrinol. Metab., 295 (2) (2008), pp. E505-E513

B.Y. Lee, N. AI-Waili, D. Stubbs, K. Wendell, G. Butler, T. Al-Waili, et al.

Ultra-low microcurrent in the management of diabetes mellitus, hypertension and chronic wounds: report of twelve cases and discussion of mechanism of action 
Int. J. Med. Sci., 2009 (7) (2009), pp. 29-35

[47]

J.L. Jarvie, M.A. Whooley, M.C. Regan, N.L. Sin, B.E. Cohen

Effect of physical activity level on biomarkers of inflammation and insulin resistance over 5 years in outpatients with coronary heart disease (from the Heart and Soul Study)

Am. J. Cardiol., 114 (2014), pp. 1192-1197

[48]

J.E. Donnelly, S.N. Blair, J.M. Jakicic, M.M. Manore, J.W. Rankin, B.K. Smith

American College of Sports Medicine Position Stand. Appropriate physical activity intervention strategies for weight loss and prevention of weight regain for adults

Med. Sci. Sports Exerc., 41 (2009), pp. 459-471

I. Ismail, S.E. Keating, M.K. Baker, N.A. Johnson

A systematic review and meta-analysis of the effect of aerobic vs. resistance exercise training on visceral fat

Obes. Rev., 13 (2012), pp. 68-91

[50]

F. Dutheil, G. Lac, B. Lesourd, R. Chapier, G. Walther, A. Vinet, et al.

Different modalities of exercise to reduce visceral fat mass and cardiovascular risk in metabolic syndrome: the RESOLVE* randomized trial

Int. J. Cardiol., 168 (4) (2013), pp. 3634-3642

[51]

V. Barrese, M. Taglialatela

New advances in beta-blocker therapy in heart failure

Front. Physiol., 4 (2013), p. 323 
C.J. Sidney Smith, E.J. Benjamin, R.O. Bonow, L.T. Braun, M.A. Creager, B.A. Franklin, et al.

AHA/ACCF secondary prevention and risk reduction therapy for patients with coronary and other atherosclerotic vascular disease: 2011 update: a guideline from the American Heart Association and American College of Cardiology Foundation endorsed by the World Heart Federation and the Preventive Cardiovascular Nurses Association

J. Am. Coll. Cardiol., 58 (23) (2011), pp. 2432-2446

A.H. Lichtenstein, L.J. Appel, M. Brands, M. Carnethon, S. Daniels, H.A. Franch, et al.

Diet and lifestyle recommendations revision

Circulation, 114 (1) (2006), pp. 82-96

[54]

N. Oliveira, F. Ribeiro, M. Teixeira, L. Campos, A.J. Alves, G. Silva, et al. Effect of 8-week exercise-based cardiac rehabilitation on cardiac autonomic function: a randomized controlled trial in myocardial infarction patients Am. Heart J., 167 (5) (2014), pp. 753-761.e3

[55]

J. Woodgate, L.R. Brawley

Self-efficacy for exercise in cardiac rehabilitation: review and recommendations

J. Health Psychol., 13 (2008), pp. 366-387 